\title{
CERTIFICAÇÃO ISO 14001: ANÁLISE DOS FATORES RÉLACIONADOS À CONSCIENTIZAÇÃO AMBIENTAL DE COLABORADORES DE UMA INDÚSTRIA DE PAPEL DA REGIÃO CENTRO-SUL DO PARANÁ
}

\author{
ISO 14001 CERTIFICATION: \\ ANALYSIS OF THE FACTORS RELATED TO THE \\ EMPLOYEES AWARENESS TO THE ENVIRONMENTAL OF \\ A PAPER INDUSTRY ON THE CENTER - \\ SOUTH REGION OF PARANÁ
}

Data de submissão: 18/05/2017 Aceite: $22 / 10 / 2017$

Katiane Crotti ${ }^{1}$

Marlete Beatriz Maçaneiro ${ }^{2}$

Marcos Roberto Kuhl ${ }^{3}$

\section{RESUMO}

Os sistemas de gestão ambiental certificados pela NBR ISO 14001:2004 surgem como alternativas para que as organizações estruturem suas atividades ambientais. Para tanto, a certificação exige um fator primordial, que é a conscientização ambiental. Diante disso, esta pesquisa objetiva identificar e analisar os fatores relacionados à conscientização ambiental de colaboradores inseridos no processo de certificação da ISO 14001, em uma indústria de papel da região Centro-Sul do Paraná. A fim de atingir os objetivos propostos, empregou-se abordagem quantitativa, com aplicação de questionários aos colaboradores da indústria pesquisada. Já o tratamento dos dados ocorreu por meio de estatística descritiva, sendo utilizados os parâmetros de média, desvio-padrão e coeficiente de variação, bem como a análise fatorial para agrupamento e análise dos fatores que mais evidenciavam a conscientização e testes para validação da escala. Como resultados, identificaram-se os fatores relacionados à conscientização ambiental, os quais foram repassados aos colaboradores via treinamentos, divulgações internas e outros mecanismos que auxiliaram a empresa a atingir um nível satisfatório de conscientização. No entanto, verificou-se uma oportunidade para a indústria de papel aprimorar a conscientização quanto ao fator gestão de resíduos, efluentes e químicos, já que nem todos os colaboradores conhecem o destino e o tratamento dado aos resíduos no final de processo.

Palavras-chave: NBR ISO 14001:2004; conscientização ambiental; indústria de papel; sistemas de gestão ambiental.

\footnotetext{
1 Possui graduação em Secretariado Executivo pela Universidade Estadual do Centro-Oeste, UNICENTRO e mestrado profissional em andamento em Administração pela Universidade Estadual do Centro-Oeste, UNICENTRO. Guarapuava. Paraná. Brasil. E-mail: katycrotti@hotmail.com 2 Possui graduação em Secretariado Executivo pela Universidade Estadual do Oeste do Paraná - UNIOESTE, mestrado em Administração pela Universidade Federal do Paraná - UFPR, doutorado em Administração pela UFPR e pós-doutorado na Universidade Positivo, pelo Programa Nacional de Pós-Doutorado. Atualmente é professora com dedicação exclusiva na Universidade Estadual do Centro-Oeste - UNICENTRO - Guarapuava-PR, do Programa de Pós-Graduação em Administração - Mestrado Profissional da UNICENTRO e do Programa de Pós-Graduação em Propriedade Intelectual e Transferência de Tecnologia para Inovação - PROFNIT. Guarapuava. Paraná. Brasil. E-mail: marlete.beatriz@yahoo.com.br 3 Possui graduação em Ciências Contábeis pela Universidade Estadual do Centro-Oeste, UNICENTRO, mestrado em Ciências Contábeis pela Universidade Federal do Paraná, UFPR e doutorado em Administração pela Universidade Federal do Paraná, UFPR. Guarapuava. Paraná. Brasil. E-mail: marcosrobertokuhl@yahoo.com.br
} 


\section{ABSTRACT}

Environmental management systems certified by NBR ISO 14001:2004 emerge as alternatives for organizations to structure their environmental activities. The certification requires a primordial factor, which is environmental awareness. Given this, this research aims to identify and analyze the factors related to the environmental awareness of employees included in the ISO 14001 certification process, on a paper industry of the Center-South region of Paraná. In order to achieve the proposed objectives, we applied a quantitative approach by the application of questionnaires to the employees of the industry researched. The treatment of the data occurred by means of descriptive statistics, being used the parameters of average, standard deviation and coefficient of variation, as well as the factor analysis for grouping and analysis of factors that showed more awareness and testing validation of the scale. As a result, they identified the factors related to environmental awareness, which were passed on to the employees by training, internal disclosures and other mechanisms that helped the company to achieve a satisfactory level of awareness. However, there was an opportunity for the paper industry to enhance awareness to waste management, wastewater and chemicals, since not all employees know the destination and the treatment of waste at the end of process.

Keywords: BR ISO 14001:2004; environmental awareness; paper industry; environmental management systems.

\section{INTRODUÇÃO}

A ascensão das atividades industriais e, por consequência, o aumento da emissão de poluentes fomentaram o desenvolvimento de processos produtivos que satisfaçam às necessidades ambientais. Além disso, as demandas da sociedade pela preservação do meio ambiente e por qualidade de vida colaboraram para que as indústrias repensassem seus processos (CAPPARELLI, 2010; JERÔNIMO, 2014).

Acrescenta-se a isso a preocupação das organizações quanto à sua imagem corporativa junto aos seus clientes, o que as leva a desenvolverem produtos, serviços e processos que incluam o respeito ao meio ambiente (OLIVEIRA; SERRA, 2010; TO; TANG, 2014). Para tanto, necessitam alinhar as estratégias organizacionais e as questões ambientais (CARDOSO et al., 2013).

Nessa perspectiva, adotar a gestão ambiental como prática permite às organizações introduzir a variável ambiental nas atividades estratégicas, o que pode diminuir os desperdícios de recursos naturais, que estão cada vez mais escassos, e também reduzir custos (ALPERSTEDT; QUINTELLA; SOUZA, 2010; JERÔNIMO, 2014). Assim, investir na gestão ambiental é uma das alternativas adotadas por empresas que buscam organizar, planejar e, ao mesmo tempo, modernizar as atividades passíveis de gerar impactos ambientais (JABBOUR; SANTOS, 2013; OLIVEIRA; SERRA, 2010).

Sob tal enfoque, as organizações necessitam sistematizar suas atividades, ou seja, desenvolver um sistema de gestão ambiental (SGA) que contemple estratégias, ações e programas voltados para a preservação do meio ambiente. O SGA consiste em uma forma de gestão que facilita o alcance dos objetivos ambientais, promove a melhoria contínua, formaliza processos e monitora as atividades que causam impactos ambientais (ABNT, 2004; OLIVEIRA; PINHEIRO, 2010).

Entretanto, para conquistar maior credibilidade no mercado, as organizações buscam certificar os seus SGAs em Normas Brasileiras (NBR) como a ISO 14001 (MAZZA; ISIDRO- FILHO; HOFFMANN, 2014). De acordo com ABNT (2004), essa norma tem como finalidade garantir a qualidade ambiental nas organizações por meio da padronização de processos e do acompanhamento das atividades. Para que seja possível conquistar a certificação, é necessário atender aos requisitos estabelecidos na norma, os quais compreendem um processo evolutivo distribuído em 
cinco etapas: a política ambiental; o planejamento; a implementação e operação; a verificação e ação corretiva; e a análise crítica pela administração (ABNT, 2004).

Dentre os requisitos da NBR ISO 14001, um dos elementos essenciais para que as organizações obtenham a certificação é o processo de conscientização, que pode ser compreendido como o ato de tornar-se consciente, de passar, segundo o Dicionário Online de Português (2017), a saber de algo, ou seja, estar informado. Entendendo que a certificação ISO 14001:2004 requer mudanças de comportamento e cultura, é relevante compreender os fatores que compõem a conscientização ambiental para fins de certificação.

Desse modo, esta pesquisa constitui um estudo de caso realizado em uma indústria de papel da região Centro-Sul do Paraná, considerada de grande porte tendo em vista a classificação por número de empregados (SEBRAE, 2013). Essa indústria, que fabrica papel-cartão para o setor de embalagens, materiais promocionais, livros e outros produtos da indústria gráfica, foi escolhida devido à intensa utilização que faz dos recursos naturais e ao fato de pertencer a um setor considerado de atividade altamente poluidora, de acordo com a Lei n.․ 6.938, de 31 de agosto de 1981 (BRASIL, 1981).

Assim, o questionamento norteador deste estudo visa investigar: quais fatores relacionados à conscientização foram necessários para que a indústria pesquisada conquistasse a certificação da ISO 14001:2004? Para tanto, o objetivo geral da pesquisa consiste em identificar e analisar os fatores relacionados à conscientização ambiental de colaboradores inseridos no processo de certificação da ISO 14001:2004, em uma indústria de papel da região Centro-Sul do Paraná.

Este estudo se justifica por investigar como a indústria analisada realizou a conscientização de seus colaboradores e quais fatores fizeram parte desse processo, podendo, portanto, ser uma oportunidade para que a indústria identifique os aspectos em relação aos quais ainda há necessidade de conscientização. Além disso, o levantamento dos fatores para o alcance da conscientização ambiental nos processos de certificação da NBR ISO 14001 pode servir de referência às organizações que estão buscando essa certificação.

\section{REVISÃO DE LITERATURA 2.1 SISTEMAS DE GESTÃO AMBIENTAL}

As organizações têm alterado a maneira como conduzem seus negócios, principalmente nas tratativas que se referem ao meio ambiente. Por essa razão, nos processos de gestão são inclusos aspectos que visem preservar o meio ambiente e, consequentemente, atender aos diversos públicos com os quais as organizações possuem relações (ALPERSTEDT; QUINTELLA; SOUZA, 2010; JERÔNIMO 2014).

Outro fator que conduz as organizações a atuarem em prol das necessidades ambientais refere-se à preocupação em manter uma boa imagem corporativa junto à sociedade e aos clientes. Sob tal enfoque, a inclusão em seus produtos e serviços do zelo com o meio ambiente pode contribuir para a manutenção de sua imagem corporativa (CARDOSO et al., 2013).

A esse respeito, Kushwaha (2010) acrescenta que os consumidores estão cada vez mais conscientes dos aspectos ambientais, buscando conhecer os produtos que adquirem. Assim, essas atitudes dos consumidores "vem transformando o ambiente industrial, dificultando a sobrevivência de empresas que insistem em se manter na abordagem tradicional do gerenciamento [...]" (JERÔNIMO, 2014, p. 72).

Além das exigências da sociedade e da busca pela boa imagem, as empresas sentem-se pressionadas a cumprir a legislação ambiental. Tal pressão demanda um comportamento mais dinâmico, apresentando-se, ao mesmo tempo, como uma oportunidade de negócios que podem trazer resultados bastante favoráveis (FERREIRA, 2013). 
Desse modo, exige-se das organizações a inclusão das questões ambientais em suas estratégias e seus objetivos organizacionais, procurando "conciliar o desenvolvimento e o respeito ao meio ambiente" (CARDOSO et al., 2013, p. 7), o que pode ser obtido por meio da prática de gestão ambiental, que permite eliminar desperdícios e reduzir custos (JERÔNIMO, 2014). Segundo Quintana et al. (2014, p. 10),

a gestão ambiental está composta por um conjunto das atividades administrativas e operacionais, que envolvem planejamento, direção, controle, alocação de recursos e outras realizadas, com o objetivo de obter efeitos positivos sobre o meio ambiente, procurando reduzir ou eliminar os danos causados pelas ações humanas.

Nesse sentido, os SGAs, quando implementados nas organizações, auxiliam na consecução dos objetivos ambientais e melhoram as operações industriais sem deixar de preservar o meio ambiente (ALBERTON; COSTA JUNIOR, 2007; OLIVEIRA; PINHEIRO, 2010). De acordo com a ABNT (2004) e com Oliveira e Pinheiro (2010), o SGA é uma forma de gestão que tem como finalidade gerir os fatores ambientais, formalizar procedimentos, promover a melhoria contínua e monitorar as atividades ambientais. Dessa maneira, um SGA estruturado pode proporcionar menor consumo dos recursos naturais e reduzir a emissão de resíduos.

No entanto, a implantação de um SGA requer investimentos na área ambiental e principalmente na conscientização de pessoas (AGUIAR, 2004). Tais investimentos proporcionam benefícios econômicos e estratégicos, que refletem em redução de custos e ganhos mercadológicos futuros (ALBERTON; COSTA JUNIOR, 2007). Para Mattiolo (2012), a gestão ambiental também é primordial para que as organizações compreendam melhor as relações que suas operações possuem com o meio ambiente, visando aprimorar seu desempenho ambiental.

Nesse contexto, além de aderir às práticas de gestão ambiental, as empresas buscam legitimar suas ações por meio de certificações como a ISO 14001 (MAZZA; ISIDRO- FILHO; HOFFMANN, 2014).. Na sequência, apresentam-se os requisitos necessários à certificação, bem como a importância da certificação para o ambiente corporativo.

\subsection{CERTIFICAÇÃO ISO 14001: REQUISITOS}

Nos últimos anos, a norma ISO 14001 teve um grande crescimento no cenário internacional (HERAS-SAIZARBITORIA; LANDÍN; MOLINA-AZORÍN, 2011), justamente por se aplicar a todas às organizações, independentemente do seu segmento e porte (CAPPARELLI, 2010). A adoção da certificação ISO 14001 consiste em uma iniciativa voluntária das organizações, considerada assim como um mecanismo de autorregulação (HERAS-SAIZARBITORIA; LANDÍN; MOLINA AZORÍN, 2011).

Segundo Borba (2007) e Capparelli (2010), as organizações que aderem a essa certificação estão comprometidas com um processo de melhoria contínua das condições de suas atividades operacionais e ainda conseguem sensibilizar e conscientizar seus colaboradores quanto à importância e responsabilidade de cada agente na cadeia do processo produtivo. Heras-Saizarbitoria, Landín e Molina-Azorín (2011) ressaltam que, atualmente, verificam-se inúmeros estudos que relatam os principais motivadores para a adoção de iniciativas de autorregulação, como é o caso da ISO 14001. Para esses autores, os mecanismos de autorregulação adotados pelas organizações originam-se das pressões de natureza externa, como clientes, fornecedores e administração pública, que demandam das organizações produtos que sejam advindos de operações ambientalmente corretas.

To e Tang (2014), por sua vez, ressaltam que as principais motivações para implantar a certificação são a conscientização ambiental dos colaboradores, que pode trazer reduções de 
consumo de matéria-prima e de poluição; a conformidade com a legislação ambiental; e a melhoria da eficiência ambiental. Sobre o tema, Aguiar e Cortês (2014, p. 33) mencionam que

A certificação de sistemas de gestão ambiental é um dos instrumentos utilizados pelas empresas que desejam implantar sistemas voltados ao cumprimento de requisitos legais relacionados à prevenção da poluição e demais exigências ambientais associadas.

Assim, nota-se que a implantação do SGA, bem como sua certificação, consiste em processos adotados pelas organizações para alcançar reconhecimento diante do mercado (GAVRONSKI, 2003). Dessa forma, a certificação pode transparecer a responsabilidade da organização com o meio, tornando-se um recurso de marketing (DARNALL, 2006; LOPES et al., 2015). Porém, para obter a certificação, a NBR ISO 14001:2004 determina alguns requisitos e fases de implantação, apresentados a seguir no Quadro 1.

A preocupação da norma ao estabelecer os requisitos para a certificação é propor um modelo de gestão que seja ambientalmente responsável, facilite o cumprimento da legislação, promova a melhoria contínua e previna a poluição (BARTHOLOMEU FILHO; AGUIAR, 2013). Nesse sentido, a norma prevê que as organizações a serem certificadas instaurem, implementem, registrem e desenvolvam continuamente um SGA que atenda aos requisitos propostos (ABNT, 2004; MAZZA; ISIDRO-FILHO; HOFFMANN, 2014).

Quadro 1: Fases para construção de um SGA

\begin{tabular}{|c|c|}
\hline FASES & REQUISITOS \\
\hline Política ambiental & $\begin{array}{l}\text { Nessa fase, a alta administração precisa estar engajada com a implantação para, } \\
\text { assim, elaborar uma política ambiental e determinar mecanismos para que esta } \\
\text { seja cumprida. De acordo com a ABNT (2004), a política ambiental deve conside- } \\
\text { rar os impactos de atividades, produtos e serviços; o comprometimento com a } \\
\text { preservação do meio ambiente e a melhoria contínua; o atendimento às exigên- } \\
\text { cias legais; e a definição de objetivos e metas ambientais; devendo, ainda, ser for- } \\
\text { malizada, efetivada, comunicada e disponibiliza a todos. }\end{array}$ \\
\hline Planejamento & $\begin{array}{l}\text { Para a ABNT (2004) e Neves e Rozemberg (2010), nessa etapa há a necessidade } \\
\text { de estabelecer objetivos e metas ambientais; levantar os aspectos e impactos } \\
\text { ambientais das operações da organização; e realizar o planejamento dos recursos } \\
\text { financeiros e de estrutura para possibilitar a implantação da política. }\end{array}$ \\
\hline $\begin{array}{l}\text { Implementação e } \\
\text { operação }\end{array}$ & $\begin{array}{l}\text { Já nessa fase a ABNT (2004) orienta que sejam definidas as responsabilidades, } \\
\text { funções e autoridades. Além disso, as organizações precisam determinar como } \\
\text { serão realizados os processos de conscientização, comunicação com o ambiente } \\
\text { interno e externo e controle de documentos, devendo, também, desenvolver um } \\
\text { plano de respostas às emergências. }\end{array}$ \\
\hline $\begin{array}{c}\text { Verificação e ação } \\
\text { corretiva }\end{array}$ & $\begin{array}{l}\text { Segundo Neves e Rozemberg (2010), as organizações devem medir, avaliar e moni- } \\
\text { torar o seu desempenho ambiental. Por essa razão, torna-se essencial nessa fase } \\
\text { definir indicadores que mensurem a eficácia do SGA e realizar auditorias internas } \\
\text { e externas para sua manutenção e avaliação. }\end{array}$ \\
\hline $\begin{array}{l}\text { Análise crítica pela } \\
\text { administração }\end{array}$ & $\begin{array}{l}\text { Essa fase compreende a análise realizada pela alta administração, que tem como } \\
\text { finalidade atualizar e alinhar as estratégias organizacionais com os objetivos am- } \\
\text { bientais, podendo ser preciso, assim, realizar alterações na política, nos objetivos } \\
\text { e nas metas ambientais. Tal análise deve ser efetuada em períodos preestabeleci- } \\
\text { dos, para garantir sua manutenção (ABNT, 2004; NEVES; ROZEMBERG, 2010). }\end{array}$ \\
\hline
\end{tabular}

Fonte: adaptado da NBR ISO 14001 (ABNT, 2004).

A ABNT (2004) relata que a norma segue a metodologia PDCA (Plan-Do-Check-Act). Essa metodologia consiste em um trabalho gradativo que se constrói fase a fase, visando à meIhoria contínua do sistema, por meio da análise dos procedimentos e das estratégias determinadas para atender aos aspectos ambientais (NEVES; ROZEMBERG, 2010). Percebe-se que, embora 
os requisitos da norma demandem empenho e investimentos, a facilidade para atender aos aspectos da legislação ambiental e a melhoria promovida na imagem corporativa diante do mercado são vantagens significativas da certificação ISO 14001 (OLIVEIRA; SERRA, 2010; TO; TANG, 2014). Nesse contexto, entende-se que a certificação pode ser um diferencial competitivo para as organizações que buscam expandir seus negócios e desejam ser reconhecidas como ambientalmente corretas. Ademais, a certificação é uma garantia de qualidade ambiental aos clientes, pois demonstra o compromisso da organização em reduzir os impactos ambientais, preservar o meio ambiente e conscientizar seus colaboradores e a comunidade.

Portanto, pode-se afirmar que a conscientização ambiental é o primeiro passo para a conquista de um SGA certificado pela ISO 14001:2004. Assim, para explanar como este estudo, que objetiva identificar e analisar os fatores relacionados à conscientização ambiental de colaboradores inseridos no processo de certificação da ISO 14001, em uma indústria de papel da região Centro-Sul do Paraná, foi desenvolvido, apresenta-se a seguir a metodologia adotada.

\section{METODOLOGIA}

Para delineamento desta pesquisa, utilizou-se a abordagem quantitativa, que pode ser compreendida como uma maneira de medir comportamentos e opiniões por meio de questionamentos acerca de aspectos como quantidade, localização espaço-temporal, atores envolvidos e frequência (COOPER; SCHINDLER, 2011). Neste estudo, tal abordagem auxiliou na mensuração da inserção das questões ambientais no ambiente interno organizacional, visando identificar os fatores relacionados à conscientização dos colaboradores em prol da certificação ISO 14001:2004.

A escolha por investigar uma única empresa, no caso uma indústria de papel, originouse da indagação de como os requisitos da norma certificadora se aplicam e são disseminados no contexto global de uma empresa. Diante disso, a investigação desta realidade específica pode, posteriormente, ser analisada em paralelo a outros estudos.

Acrescenta-se que a escolha da indústria de papel, de porte médio, foi motivada pelo fato de ser uma empresa de destaque na região Centro-Sul do Paraná e de se pressupor que, por ser um segmento em que as atividades possuem alto impacto no meio ambiente, a conquista de certificação tenha envolvido diversas mudanças no ambiente interno da organização.

Para tanto, o instrumento adotado para a coleta de dados foi o questionário, que, segundo Creswell (2010), tem como objetivo realizar um levantamento numérico que permite testes e análises quantitativas. O questionário utilizado era composto de 30 afirmativas, nas quais os colaboradores poderiam marcar uma opção dentro da escala Likert de sete pontos, que varia de discordo totalmente a concordo totalmente.

A construção desse instrumento de pesquisa ocorreu a partir dos requisitos exigidos pela NBR ISO 14001, pois, em todas as etapas do processo de certificação, existem elementos que demandam conscientização. O questionário foi avaliado por dois professores com conhecimento sobre o tema, e ambos fizeram sugestões, que foram acatadas. Também se realizaram pré-testes com quatro colaboradores, selecionados aleatoriamente, para ajustes do instrumento.

O questionário foi aplicado em todas as três unidades que a indústria de papel em questão possui. No momento da aplicação, a indústria recentemente havia obtido a certificação, o que auxiliou na mensuração da efetividade de todo o processo realizado para essa conquista. O questionário visou investigar a percepção dos colaboradores quanto à inserção das questões ambientais no dia a dia de trabalho, buscando identificar se a preocupação e conscientização ambiental são elementos presentes ou não nas rotinas da empresa. 
O questionário foi aplicado em algumas rodadas em uma sala exclusiva destinada a esse fim, no período de 23 de outubro a 18 de dezembro de 2015, conforme os turnos de trabalho dos colaboradores, cuja participação ocorreu por adesão. Ressalta-se que todos os colaboradores foram convidados a responder o questionário, não tendo sido estabelecida a aplicação para níveis hierárquicos e cargos específicos, já que a certificação envolveu a empresa como um todo.

Após a finalização da coleta de dados, foramobtidos 342 questionáriosválidos, emuma populaçãode 738 colaboradores daempresa pesquisada, dadosanalisados pormeiodeanálisesestatísticas descritivascomomédia, desvio-padrãoecoeficientedevariação,comoauxíliodopacoteestatísticoStatistical PackagefortheSocialSciences(SPSS ${ }^{\circledR}$ ).Dessaforma, aamostraébemsuperioraonúmeromínimoindicado (253) pelo cálculo da amostragem para populações finitas, com nível de confiança (Z) de 95\%, nível de precisão (e) de $5 \%$ e produto da quantidade de acertos e de erros esperados de 0,25 . No entanto, ressalta-se que o SPSS desconsidera as linhas em que existem valores ausentes na maioria das análises. Assim, a amostra corrigida passou a ser de 337 questionários válidos em média, com mínimo de 314 quando analisados em conjunto.

Com relação à caracterização da amostra, $67 \%$ dos participantes são do gênero masculino, e 33\%, do gênero feminino. Quanto às faixas etárias dos respondentes, estas estão bem distribuídas: 26,5\% correspondem à faixa de 29 a 36 anos, 25,3\% possuem acima de 37 anos, $24,4 \%$ têm de 23 a 28 anos, e $23,8 \%$ possuem de 18 a 22 anos.

Além disso, utilizou-se a estatística inferencial da Análise Fatorial Exploratória (AFE), uma técnica de análise que possibilita reduzir o número de variáveis por meio da identificação de grupos ou agrupamentos (fatores) dessas variáveis, a partir do grau de correlação entre elas (MAROCO, 2003; FIELD, 2009). Nessa análise, levantaram-se os coeficientes de correlação altos entre as variáveis que deixaram em evidência os fatores ou as chamadas variáveis latentes (FIELD, 2009). Para identificar a viabilidade da AFE, efetuaram-se testes como Kaiser Meyer-Olkim (KMO) e Bartlett.

Sob tal enfoque, buscou-se levantar os fatores que mais evidenciavam a conscientização dos colaboradores quanto aos aspectos ambientais para a implantação da ISO 14001. Assim, os valores da estatística descritiva (média e desvio-padrão), que identificam os fatores gerados pela AFE, são apresentados nas Tabelas 2, 3, 4, 5, 6, 7, 8, 9 e 10.

Entretanto, tendo em vista que o questionário foi elaborado com 30 questões, representando uma variável para cada questão, foi preciso reduzir este número para que as análises fossem mais precisas. Seguindo as sugestões de Maroco (2003) e de Field (2009), para identificar a viabilidade da utilização da AFE, foram realizados os testes de KMO e de Bartlett, e a extração dos fatores foi feita utilizando o método dos componentes principais, com eigenvalues de 1 e rotação Varimax.

Por fim, para validar a confiabilidade da escala, foi utilizado o coeficiente alfa de Cronbach, que, segundo Field (2009), consiste em uma medida bastante comum para verificar a confiabilidade. Considera-se como resultados confiáveis um índice acima de 0,6 , enquanto que valores abaixo indicam que os achados não são confiáveis.

\section{ANÁLISE DOS DADOS - OS FATORES DE CONSCIENTI- ZAÇÃO AMBIENTAL}

Na sequência, são abordados os fatores relacionados à conscientização ambiental inseridos no processo de certificação da ISO 14001:2004 da indústria de papel pesquisada. Considerando que a implantação dessa certificação demanda o atendimento de diversos requisitos e adequações internas, a conscientização ambiental configura-se o fator-chave para o sucesso desse processo (AGUIAR, 2004; TO; TANG, 2014). 
Além de realizar o levantamento dos fatores, torna-se relevante mencionar que, durante as visitas realizadas para aplicação dos questionários, foram observadas algumas práticas e meios para divulgação e conscientização ambiental. Verificaram-se nos murais e informativos internos: a disseminação da política ambiental; editais de convocações para treinamentos; campanhas de preservação dos recursos naturais; e campanhas de gestão dos resíduos e de coleta seletiva.

Outras ferramentas também foram observadas, tais como: adesivos próximos às tomadas com frases de conscientização; placas espalhadas nas dependências da empresa; placas informando sobre ações de emergência; e placas que indicam a presença de kits de emergência no caso de contato com produtos químicos ou derramamento no solo. Essas práticas demonstram elementos que fazem parte do processo de gestão ambiental realizado pela indústria, o qual, segundo Quintana et al. (2014), compreende o conjunto das atividades administrativas e operacionais, com a finalidade de conscientizar e reduzir os impactos ao meio ambiente.

Os fatores relacionados à conscientização ambiental de colaboradores foram agrupados e tratados por meio da AFE, realizando-se, para identificar a viabilidade dessa análise, o teste de KMO. Segundo Kaiser (1974 apud FIELD, 2009, p. 579), para o KMO, "os valores entre 0,5 e 0,7 são medíocres, valores entre 0,7 e 0,8 são bons, valores entre 0,8 e 0,9 são ótimos e valores acima de 0,9 são excelentes". A Tabela 1 apresenta o resultado do teste de KMO e de Bartlett.

Tabela 1 - Resultado do KMO e do Teste de Bartlett

\begin{tabular}{c|c|c}
\hline \multicolumn{2}{c}{ KMO and Bartlett's Test } & 0,740 \\
\hline Kaiser-Meyer-Olkin Measure of Sampling Adequacy. & 2171,322 \\
\hline Bartlett's Test of Sphericity & Approx. Chi-Square & 435,000 \\
\hline & df & 0,000 \\
\hline
\end{tabular}

Fonte: saída do SPSS.

Considerando os valores apresentados na Tabela 1, especialmente o valor do KMO $(0,740)$, "devemos estar confiantes de que a análise dos fatores é apropriada para esses dados" (FIELD, 2009, p. 579). Além dos valores apresentados na Tabela 1, é relevante destacar que a variância total explicada do conjunto de fatores identificados pela AFE foi de $59,18 \%$. Assim, a AFE indicou a existência de nove fatores, conforme os dados apresentados nas Tabelas 2 a 11. As denominações dos fatores foram realizadas pelos pesquisadores, de acordo com a similaridade de assuntos abordados nas questões.

Na Tabela 2, a seguir, é apresentado o fator 1, denominado gestão de resíduos, efluentes e químicos.

Tabela 2 - Fator 1 - Gestão de resíduos, efluentes e químicos

\begin{tabular}{c|c|c|c|c}
\hline \multicolumn{2}{c|}{ VARIÁVEIS } & $\begin{array}{c}\text { Carrega- } \\
\text { mento }\end{array}$ & Média & $\begin{array}{c}\text { Desvio } \\
\text {-padrão }\end{array}$ \\
\hline Q23 & Conheço como a empresa realiza a gestão dos efluentes. & 0,825 & 5,91 & 1,122 \\
\hline Q22 & Conheço como a empresa realiza a gestão dos resíduos. & 0,737 & 5,92 & 1,087 \\
\hline Q27 & Conheço os locais de armazenamento dos produtos químicos. & 0,647 & 5,94 & 1,225 \\
\hline Q25 & A empresa utiliza materiais reciclados para produzir seus produtos. & 0,654 & 6,30 & 0,975 \\
\hline \multicolumn{2}{c|}{ Variância explicada (AFE) } & \multicolumn{3}{|c}{$7,50 \%$} \\
\hline \multirow{2}{*}{ Alfa de Cronbach } & Índice & \multicolumn{3}{c}{4} \\
\cline { 2 - 5 } & $\mathrm{N}$. o de itens & \multicolumn{3}{c}{314} \\
\cline { 2 - 5 }
\end{tabular}

Fonte: elaboração própria. 
A verificação da consistência interna ou confiabilidade da escala foi feita por meio do alfa de Cronbach, que é "a medida mais comum de confiabilidade" (FIELD, 2009, p. 594). Segundo Field (2009, p. 594), "um valor de 0,7-0,8 é aceitável para o $\alpha$ de Cronbach e valores substancialmente mais baixos indicam uma escala não confiável". Para Malhotra (2006), o valor esperado de confiabilidade é no mínimo 0,6, e valores inferiores podem indicar uma consistência interna insatisfatória.

Neste caso, o valor do alfa de Cronbach foi adequado para esse conjunto de dados. Além disso, o SPSS indica se alguma das variáveis que compõem o fator deve ser excluída para que o valor do alfa seja amplificado. No entanto, ao analisar os dados, verificou-se que a exclusão de qualquer uma das variáveis não geraria uma melhora significativa no valor do alfa de Cronbach.

Assim, a média dos questionamentos mostra que colaboradores concordam em partes, ou seja, que nem todos conhecem adequadamente como é realizada a gestão de resíduos, efluentes e químicos na indústria em questão. Isso pode ser justificado por se tratar de elementos de final de processo, com os quais a maioria dos colaboradores não possui envolvimento direto. Contudo, ressalta-se a relevância de todos estarem cientes de como a empresa realiza tais processos, pois esses conhecimentos fazem parte da gestão ambiental, e entender as relações que as atividades da empresa possuem com o meio ambiente pode auxiliar no comprometimento de todos e na performance ambiental (MATTIOLO, 2012). Ademais, conforme menciona Jerônimo (2014), a presença da variável ambiental na organização pode gerar ganhos em relação à redução de desperdícios e custos.

No entanto, a variável Q25 destacou-se com média 6,3, permitindo inferir que, além da conscientização, a utilização de materiais reciclados está presente no dia a dia dos colaboradores, ou seja, nas rotinas e nos processos que realizam, justificando a média apresentada. Hoje, a empresa desenvolve uma linha específica de produtos que utiliza de aparas de papel, um material proveniente do pós-consumo. As aparas consistem em papéis já utilizados ou nas sobras dos cortes, que podem ser reaproveitadas para a fabricação de novos produtos desde que estejam em boa condição.

Assim, por meio das variáveis analisadas, buscou-se compreender se atitudes simples, mas que possuem impacto no meio ambiente, estão disseminadas entre os colaboradores. De acordo com observações realizadas na indústria pesquisada, tais iniciativas são estimuladas em treinamentos, placas, adesivos e folders. A Tabela 3 aponta como está a conscientização ambiental dos colaboradores em relação a situações do dia a dia.

Tabela 3 - Fator 2 - Iniciativas de preocupação ambiental

\begin{tabular}{|c|c|c|c|c|c|}
\hline \multicolumn{3}{|c|}{ VARIÁVEIS } & Carrega-mento & Média & Desvio-padrão \\
\hline Q18 & \multicolumn{2}{|c|}{$\begin{array}{c}\text { Ao passar por uma torneira pingando, eu paro } \\
\text { para fechar. }\end{array}$} & 0,701 & 6,71 & 0,601 \\
\hline Q17 & \multicolumn{2}{|c|}{ Apago as luzes quando saio de um ambiente. } & 0,685 & 6,65 & 0,653 \\
\hline Q19 & \multicolumn{2}{|c|}{ Procuro não gerar desperdícios. } & 0,624 & 6,34 & 0,628 \\
\hline Q16 & \multicolumn{2}{|c|}{$\begin{array}{l}\text { Antes de jogar algo no lixo, penso em como pode- } \\
\text { ria reutilizá-lo. }\end{array}$} & 0,562 & 6,15 & 0,914 \\
\hline \multicolumn{3}{|c|}{ Variância explicada (AFE) } & \multicolumn{3}{|c|}{$7,37 \%$} \\
\hline \multirow{3}{*}{\multicolumn{2}{|c|}{ Alfa de Cronbach }} & Índice & \multicolumn{3}{|c|}{0,631} \\
\hline & & N.o de itens & \multicolumn{3}{|c|}{4} \\
\hline & & $\mathrm{N}$ & \multicolumn{3}{|c|}{333} \\
\hline
\end{tabular}

Fonte: elaboração própria. 
Da mesma forma que no fator 1, o valor do alfa de Cronbach do fator 2 é aceitável, não existindo a indicação de exclusão de nenhuma das variáveis para melhoria desse fator. A partir das médias e do desvio-padrão, observa-se que há coerência entre os respondentes quanto à conscientização individual no que diz respeito a aspectos básicos do dia a dia. $\mathrm{O}$ trabalho de conscientização possivelmente realizado pode ter levado os respondentes a concordarem em grande parte com as afirmativas. Isso demonstra que os meios e as práticas empregados pela empresa, citados no início da análise, auxiliaram na conscientização dos seus colaboradores e, consequentemente, na conquista da certificação (AGUIAR, 2004; TO; TANG, 2014).

A Tabela 4 apresenta como está a conscientização em relação à importância da certificação para empresa, bem como o nível de conscientização sobre a política ambiental por ela adotada. Neste fator, estão as variáveis que representam elementos presentes no primeiro requisito da norma, que trata da definição e disseminação de uma política ambiental.

Tabela 4 - Fator 3 - Política ambiental

\begin{tabular}{|c|c|c|c|c|c|}
\hline \multicolumn{3}{|c|}{ VARIÁVEIS } & $\begin{array}{l}\text { Carrega- } \\
\text { mento }\end{array}$ & Média & $\begin{array}{l}\text { Desvio } \\
\text {-padrão }\end{array}$ \\
\hline Q13 & \multicolumn{2}{|c|}{ Entendo a importância da certificação ISO 14001:2004 para a empresa. } & 0,738 & 6,60 & 0,734 \\
\hline Q12 & \multicolumn{2}{|c|}{$\begin{array}{c}\text { Nos treinamentos, as informações sobre a certificação da ISO } \\
\text { 14001:2004 foram passadas de maneira clara. }\end{array}$} & 0,684 & 6,36 & 0,895 \\
\hline Q08 & \multicolumn{2}{|c|}{ Conheço a política ambiental da organização. } & 0,507 & 6,29 & 0,857 \\
\hline Q07 & \multicolumn{2}{|c|}{ A empresa comunica a sua política ambiental. } & 0,403 & 6,79 & 0,478 \\
\hline \multicolumn{3}{|c|}{ Variância explicada (AFE) } & \multicolumn{3}{|c|}{$7,31 \%$} \\
\hline \multirow{3}{*}{\multicolumn{2}{|c|}{ Alfa de Cronbach }} & Índice & \multicolumn{3}{|c|}{0,656} \\
\hline & & N.. de itens & \multicolumn{3}{|c|}{4} \\
\hline & & $\mathrm{N}$ & \multicolumn{3}{|c|}{330} \\
\hline
\end{tabular}

Fonte: elaboração própria.

Nos dados da Tabela 4, novamente o índice do alfa de Cronbach ficou dentro do limite do aceitável, não havendo indicação de exclusão de qualquer uma das variáveis. As afirmativas das questões 07, 08, 12 e 13 remetiam diretamente à implantação da certificação ISO 14001, com as quais os colaboradores indicaram que concordavam em grande parte, demonstrando que compreendem a importância da certificação para a empresa. Isso corrobora o apontado por Borba (2007) e Capparelli (2010), ao mencionarem que por meio da certificação é possível sensibilizar os colaboradores quanto à importância e responsabilidade de cada um no processo de gestão ambiental. Além disso, as médias indicam que a indústria em análise conseguiu alcançar a conscientização da política ambiental, uma vez que esta foi formalizada na forma escrita e divulgada a todos os colaboradores (ABNT, 2004).

Já para conhecer a percepção dos colaboradores quanto ao comprometimento da indústria com as questões ambientais, realizaram-se quatro questões, cujas suas médias e cujo desvio-padrão são apresentados na Tabela 5. 
Tabela 5 - Fator 4 - Percepção do comprometimento da empresa

\begin{tabular}{|c|c|c|c|c|c|}
\hline \multicolumn{3}{|c|}{ VARIÁVEIS } & Carrega-mento & Média & Desvio-padrão \\
\hline Q02 & \multicolumn{2}{|c|}{$\begin{array}{l}\text { As práticas/atividades da empresa prezam pelo respei- } \\
\text { to ao meio ambiente. }\end{array}$} & 0,745 & 6,65 & 0,549 \\
\hline Q03 & \multicolumn{2}{|c|}{$\begin{array}{l}\text { Há incentivo por parte da empresa quanto à preserva- } \\
\text { ção do meio ambiente. }\end{array}$} & 0,680 & 6,68 & 0,559 \\
\hline Q01 & \multicolumn{2}{|c|}{$\begin{array}{l}\text { Observo que esta empresa é preocupada com os as- } \\
\text { pectos ambientais. }\end{array}$} & 0,668 & 6,68 & 0,539 \\
\hline Q09 & \multicolumn{2}{|c|}{$\begin{array}{l}\text { A empresa se compromete com a melhoria contínua e } \\
\text { com a prevenção da poluição. }\end{array}$} & 0,552 & 6,62 & 0,625 \\
\hline \multicolumn{3}{|c|}{ Variância explicada (AFE) } & \multicolumn{3}{|c|}{$6,98 \%$} \\
\hline \multirow{3}{*}{\multicolumn{2}{|c|}{ Alfa de Cronbach }} & Índice & \multicolumn{3}{|c|}{0,668} \\
\hline & & N.. de itens & \multicolumn{3}{|c|}{4} \\
\hline & & $\mathrm{N}$ & \multicolumn{3}{|c|}{338} \\
\hline
\end{tabular}

Fonte: elaboração própria.

Nesse agrupamento da Tabela 5, o índice do alfa de Cronbach ficou dentro do limite do aceitável, não existindo novamente indicação de exclusão de qualquer uma das variáveis. A média das questões desse fator foi bastante positiva, pois os colaboradores apontaram que concordam em grande parte que a indústria de papel em questão se compromete com o meio ambiente.

Diante disso, é possível afirmar que a indústria pesquisada, por meio da busca pela certificação ISO 14001, disseminou internamente sua preocupação e seu comprometimento com as questões ambientais. Nessa perspectiva, Alperstedt, Quintella e Souza (2010), Cardoso et al. (2013) e Jerônimo (2014) explicitam que o comprometimento ambiental proporciona uma boa imagem corporativa junto aos clientes e à sociedade, auxiliando as organizações a atenderem às demandas dos diversos públicos com os quais mantém relações.

Na Tabela 6, as questões apresentadas foram direcionadas para conhecer a percepção dos colaboradores quanto aos danos ambientais.

Tabela 6 - Fator 5 - Percepção dos danos ambientais

\begin{tabular}{|c|c|c|c|c|c|}
\hline \multicolumn{3}{|c|}{ VARIÁVEIS } & $\begin{array}{l}\text { Carrega- } \\
\text { mento }\end{array}$ & Média & $\begin{array}{l}\text { Desvio-pa- } \\
\text { drão }\end{array}$ \\
\hline Q28 & \multicolumn{2}{|c|}{$\begin{array}{l}\text { Tenho consciência do dano ambiental de um derra- } \\
\text { mamento de óleo ou produto químico. }\end{array}$} & 0,719 & 6,69 & 0,630 \\
\hline Q29 & \multicolumn{2}{|c|}{$\begin{array}{l}\text { Quando percebo um vazamento, informo os respon- } \\
\text { sáveis e solicito as manutenções necessárias. }\end{array}$} & 0,640 & 6,66 & 0,633 \\
\hline Q30 & \multicolumn{2}{|c|}{$\begin{array}{l}\text { Conheço o procedimento para situações de emergên- } \\
\text { cia e acidentes que possam causar impactos ambien- } \\
\text { tais. }\end{array}$} & 0,597 & 6,35 & 0,875 \\
\hline Q26 & \multicolumn{2}{|c|}{$\begin{array}{c}\text { A empresa se preocupa com operação, transporte e } \\
\text { manuseio dos produtos químicos. }\end{array}$} & 0,461 & 6,64 & 0,740 \\
\hline \multicolumn{3}{|c|}{ Variância explicada (AFE) } & \multicolumn{3}{|c|}{$6,44 \%$} \\
\hline \multirow{3}{*}{\multicolumn{2}{|c|}{ Alfa de Cronbach }} & Índice & \multicolumn{3}{|c|}{0,655} \\
\hline & & $\mathrm{N} . \mathrm{o}$ de itens & \multicolumn{3}{|c|}{4} \\
\hline & & $\mathrm{N}$ & \multicolumn{3}{|c|}{329} \\
\hline
\end{tabular}

Fonte: elaboração própria. 
No que concerne ao fator da Tabela 6, que trata da percepção dos colaboradores quanto aos danos ambientais, o índice do alfa de Cronbach ficou dentro do limite do aceitável, não houve exclusão de qualquer uma das variáveis. A partir das médias das variáveis, identificou-se que os colaboradores conhecem e compreendem os impactos ambientais que um vazamento e derramamento de óleo ou produto químico podem trazer, assim como conhecem o procedimento para situações de emergência e acidentes, entendendo que a indústria possui um cuidado com operação, transporte e manuseio de produtos químicos. Tais dados vão ao encontro do que defendem Oliveira e Pinheiro (2010) e Capparelli (2010), ao dizerem que procedimentos auxiliam na orientação e melhoria da conduta ambiental.

$\mathrm{Na}$ Tabela 7, as questões abordadas visaram identificar a participação dos colaboradores em treinamentos, bem como se estes auxiliaram a entender a importância da preservação do meio ambiente.

Tabela 7 - Fator 6 - Educação ambiental

\begin{tabular}{|c|c|c|c|c|c|}
\hline \multicolumn{3}{|c|}{ VARIÁVEIS } & $\begin{array}{l}\text { Carrega- } \\
\text { mento }\end{array}$ & Média & $\begin{array}{l}\text { Desvio- } \\
\text { padrão }\end{array}$ \\
\hline Q10 & \multicolumn{2}{|c|}{ Participei dos treinamentos de conscientização ambiental. } & 0,838 & 6,37 & 0,933 \\
\hline Q11 & \multicolumn{2}{|c|}{$\begin{array}{l}\text { Os treinamentos me ajudaram a entender a importância da } \\
\text { preservação do meio ambiente. }\end{array}$} & 0,704 & 6,50 & 0,844 \\
\hline Q04 & \multicolumn{2}{|c|}{$\begin{array}{l}\text { As atividades que realizo no meu dia a dia impactam o } \\
\text { meio ambiente. }\end{array}$} & 0,529 & 5,61 & 1,486 \\
\hline \multicolumn{3}{|c|}{ Variância explicada (AFE) } & \multicolumn{3}{|c|}{$6,18 \%$} \\
\hline \multirow{3}{*}{\multicolumn{2}{|c|}{ Alfa de Cronbach }} & Índice & \multicolumn{3}{|c|}{0,532} \\
\hline & & N.. de itens & \multicolumn{3}{|c|}{3} \\
\hline & & $\mathrm{N}$ & \multicolumn{3}{|c|}{330} \\
\hline
\end{tabular}

Neste fator 6, o valor do alfa de Cronbach ficou abaixo do recomendável, sendo recomendável a exclusão da variável Q04 para que o alfa de Cronbach passasse a ser de 0,781 - valor aceitável para sua validação. Assim, no restante das análises a variável Q04 foi excluída. Por meio da análise das variáveis Q10 e Q11, é perceptível que os colaboradores entendem a importância de participar de treinamentos e acreditam que estes podem auxiliar na educação ambiental. Destaca-se que treinamentos são uma das ferramentas utilizadas em um processo de conscientização, constituindo, portanto, um dos requisitos da norma certificadora (ABNT, 2004).

Verifica-se, ainda, que a maioria dos colaboradores respondentes apontou que participou em grande parte dos treinamentos realizados. Assim, pode-se inferir que a empresa, ao buscar a certificação, objetivou modernizar, planejar e organizar suas atividades ambientais (JABBOUR; SANTOS, 2013; OLIVEIRA; SERRA, 2010).

A Tabela 8 , a seguir, apresenta os dados referentes à conscientização dos colaboradores quanto às atividades de coleta seletiva e reciclagem. 
Tabela 8 - Fator 7 - Coleta seletiva e reciclagem

\begin{tabular}{|c|c|c|c|c|c|}
\hline \multicolumn{3}{|c|}{ VARIÁVEIS } & $\begin{array}{l}\text { Carrega- } \\
\text { mento }\end{array}$ & Média & $\begin{array}{l}\text { Desvio- } \\
\text { padrão }\end{array}$ \\
\hline Q14 & \multicolumn{2}{|c|}{ A empresa realiza coleta seletiva. } & 0,764 & 6,87 & 0,370 \\
\hline Q15 & \multicolumn{2}{|c|}{$\begin{array}{c}\text { Separo o lixo reciclável, como papel, plástico, alumínio, } \\
\text { vidro ou ferros. }\end{array}$} & 0,695 & 6,89 & 0,324 \\
\hline Q24 & \multicolumn{2}{|c|}{ A empresa realiza a reciclagem de materiais. } & 0,529 & 6,49 & 0,869 \\
\hline \multicolumn{3}{|c|}{ Variância explicada (AFE) } & \multicolumn{3}{|c|}{$5,91 \%$} \\
\hline \multirow{3}{*}{\multicolumn{2}{|c|}{ Alfa de Cronbach }} & Índice & \multicolumn{3}{|c|}{0,419} \\
\hline & & N.ㅇ de itens & \multicolumn{3}{|c|}{3} \\
\hline & & $\mathrm{N}$ & \multicolumn{3}{|c|}{326} \\
\hline
\end{tabular}

Fonte: elaboração própria.

Também no fator 7 o valor do alfa de Cronbach ficou muito abaixo do recomendável, existindo a indicação de exclusão da variável Q24. No entanto, segundo Hair Jr. et al. (2008, p. 200), dependendo do objetivo do estudo, valores abaixo da referência $(0,60)$, entre 0,3 e 0,6, podem ser aceitáveis.

Já as médias das variáveis Q14 e Q15 indicam que os respondentes estão cientes da existência de coleta seletiva e praticam a separação dos materiais, conforme determina o procedimento de coleta. Isso significa que a indústria em análise está cumprindo com seu papel de conscientização (AGUIAR, 2004; TO; TANG, 2014).

A Tabela 9, por sua vez, traz os valores que apontam se os colaboradores conhecem o documento denominado Levantamento de Aspectos e Impactos Ambientais (LAIA). Esse levantamento foi realizado em cada setor da indústria analisada, gerando uma tabela específica de acordo com as atividades efetuadas em cada setor e os respectivos impactos ambientais.

Tabela 9 - Fator 8 - Aspectos e impactos ambientais

\begin{tabular}{c|c|c|c|c}
\hline \multicolumn{2}{c|}{ VARIÁVEIS } & $\begin{array}{c}\text { Carrega- } \\
\text { mento }\end{array}$ & Média & $\begin{array}{c}\text { Desvio- } \\
\text { padrão }\end{array}$ \\
\hline \multirow{2}{*}{ Q21 } & $\begin{array}{c}\text { Sei onde encontrar a tabela de aspectos e impactos } \\
\text { ambientais (LAIA). }\end{array}$ & 0,810 & 6,15 & 1,019 \\
\hline \multirow{2}{*}{ Q20 } & $\begin{array}{c}\text { Conheço a tabela de Levantamento de Aspectos e } \\
\text { Impactos Ambientais (LAIA) do meu setor. }\end{array}$ & 0,722 & 5,90 & 1,097 \\
\hline \multicolumn{2}{c|}{ Variância explicada (AFE) } & \multicolumn{2}{|c}{$5,82 \%$} \\
\hline \multirow{2}{*}{ Alfa de Cronbach } & Índice & \multicolumn{2}{|c}{0,432} \\
\cline { 2 - 5 } & $\mathrm{N}$. de itens & \multicolumn{2}{|c}{324} \\
\hline
\end{tabular}

Fonte: elaboração própria.

No caso do fator 8, o valor do alfa de Cronbach foi reduzido, não havendo, entretanto, alternativa, já que o fator é composto por apenas duas variáveis. Como mencionado anteriormente, segundo Hair Jr. et al. (2008, p. 200), dependendo do objetivo do estudo, valores abaixo da referência $(0,60)$, entre 0,3 e 0,6, podem ser aceitáveis.

Torna-se interessante ressaltar que, ao passo que a média da variável Q21 aponta que os colaboradores dizem concordar em grande parte sobre onde encontrar a tabela do LAIA, a média da Q20 indica que concordam apenas em parte a respeito do conhecimento de tal tabela. Assim, verifica-se que os respondentes sabem da existência do LAIA, mas nem todos conhecem o objetivo desse levantamento. Entretanto, é importante que todos os colaboradores estejam conscientes da finalidade desse documento, pois ele identifica as relações que seus processos, produtos e demais operações possuem com o meio ambiente (ABNT, 2004; MATTIOLO, 2012). 
Na sequência, a Tabela 10 apresenta as variáveis que identificam se os colaboradores entendem que a certificação demandou adequações nas atividades e no ambiente de trabalho. Assim, a Q05 buscou levantar se, nas atividades/funções, houve adequações para atendimento dos requisitos ambientais. Já a Q06 teve como finalidade identificar se os colaboradores observaram mudanças no ambiente de trabalho, ou seja, se foram realizadas mudanças nas estruturas, máquinas, tecnologias etc.

Tabela 10 - Fator 9 - Adequações ambientais

\begin{tabular}{|c|c|c|c|c|c|}
\hline \multicolumn{3}{|c|}{ VARIÁVEIS } & $\begin{array}{l}\text { Carrega- } \\
\text { mento }\end{array}$ & Média & $\begin{array}{l}\text { Desvio- } \\
\text { padrão }\end{array}$ \\
\hline Q05 & \multicolumn{2}{|c|}{$\begin{array}{l}\text { Nas minhas atividades diárias, foram feitas adequa- } \\
\text { ções para atender aos requisitos ambientais. }\end{array}$} & 0,852 & 6,16 & 0,951 \\
\hline Q06 & \multicolumn{2}{|c|}{$\begin{array}{l}\text { No meu ambiente de trabalho, foram feitas adequa- } \\
\text { ções para atender aos requisitos ambientais. }\end{array}$} & 0,817 & 6,30 & 0,879 \\
\hline \multicolumn{3}{|c|}{ Variância explicada (AFE) } & \multicolumn{3}{|c|}{$5,65 \%$} \\
\hline \multirow{3}{*}{\multicolumn{2}{|c|}{ Alfa de Cronbach }} & Índice & \multicolumn{3}{|c|}{0,717} \\
\hline & & N.ㅇ de itens & \multicolumn{3}{|c|}{2} \\
\hline & & $\mathrm{N}$ & \multicolumn{3}{|c|}{335} \\
\hline
\end{tabular}

Fonte: elaboração própria.

Nesse fator 9, o alfa de Cronbach é aceitável, não havendo indicação de exclusão. Verifica-se, a partir das médias das variáveis, que os colaboradores afirmaram, em grande parte, que houve adequações no ambiente de trabalho e nas atividades diárias. Por essa razão, pode-se concluir que, para conquistar a certificação, a empresa em foco precisou realizar adequações e possivelmente desenvolver inovações que podem trazer benefícios à organização.

Quanto ao desenvolvimento de inovações, não é possível evidenciá-las por não ser este o foco da presente pesquisa. Entretanto, com base na literatura e no reconhecimento das adequações realizadas, sabe-se que a implantação da certificação demanda que as empresas busquem novas tecnologias e novos produtos, bem como modernizem seus processos (OLIVEIRA; SERRA, 2010).

Com a finalidade de identificar os valores de carregamento das variáveis e o agrupamento a partir da AFE, apresenta-se a Tabela 11.

Tabela 11 - Matriz de componente rotativa

\begin{tabular}{|c|c|c|c|c|c|c|c|c|c|}
\hline & \multicolumn{9}{|c|}{ Componente } \\
\hline & 1 & 2 & 3 & 4 & 5 & 6 & 7 & 8 & 9 \\
\hline Q23 & 0,825 & & & & & & & & \\
\hline Q22 & 0,737 & & & & & & & & \\
\hline Q27 & 0,647 & & & & & & & & \\
\hline Q25 & 0,554 & & & & & & & & \\
\hline Q18 & & 0,701 & & & & & & & \\
\hline Q17 & & 0,685 & & & & & & & \\
\hline Q19 & & 0,624 & & & & & & & \\
\hline Q16 & & 0,562 & & & & & & & \\
\hline Q13 & & & 0,738 & & & & & & \\
\hline Q12 & & & 0,684 & & & & & & \\
\hline Q08 & & & 0,507 & & & & & & \\
\hline
\end{tabular}


KATIANE CROTTI,

MARLETE BEATRIZ MAÇANEIRO, MARCOS ROBERTO KUHL

\begin{tabular}{|c|c|c|c|c|c|c|c|c|c|}
\hline & & & & & ompon & & & & \\
\hline & 1 & 2 & 3 & 4 & 5 & 6 & 7 & 8 & 9 \\
\hline Q07 & & & 0,503 & & & & & & \\
\hline $\mathrm{Q} 02$ & & & & 0,745 & & & & & \\
\hline Q03 & & & & 0,68 & & & & & \\
\hline Q01 & & & & 0,668 & & & & & \\
\hline Q09 & & & & 0,552 & & & & & \\
\hline Q28 & & & & & 0,719 & & & & \\
\hline Q29 & & & & & 0,64 & & & & \\
\hline Q30 & & & & & 0,597 & & & & \\
\hline Q26 & & & & & 0,561 & & & & \\
\hline Q10 & & & & & & 0,838 & & & \\
\hline Q11 & & & & & & 0,704 & & & \\
\hline Q04 & & & & & & 0,529 & & & \\
\hline Q14 & & & & & & & 0,764 & & \\
\hline Q15 & & & & & & & 0,695 & & \\
\hline Q24 & & & & & & & 0,529 & & \\
\hline Q21 & & & & & & & & 0,81 & \\
\hline Q20 & & & & & & & & 0,722 & \\
\hline $\mathrm{Q} 05$ & & & & & & & & & 0,852 \\
\hline Q06 & & & & & & & & & 0,817 \\
\hline
\end{tabular}

Fonte: elaboração própria.

Em função dos resultados apresentados nas Tabelas 2 a 10, considerando a exclusão das duas variáveis (Q04 e Q24) indicadas pelo SPSS no teste do alfa de Cronbach, a Tabela 12 apresenta a média e o desvio-padrão de cada fator.

Tabela 12 - Fatores

\begin{tabular}{c|c|c|c}
\hline Fator & Descrição dos fatores & Média & Desvio-padrão \\
\hline 1 & Gestão de resíduos, efluentes e químicos & 5,86 & 0,992 \\
\hline 2 & Iniciativas de preocupação ambiental & 6,53 & 0,506 \\
\hline 3 & Política ambiental & 6,48 & 0,559 \\
\hline 4 & Percepção do comprometimento da empresa & 6,65 & 0,407 \\
\hline 5 & Percepção dos danos ambientais & 6,57 & 0,535 \\
\hline 6 & Educação ambiental & 6,40 & 0,838 \\
\hline 7 & Coleta seletiva e reciclagem & 6,67 & 0,558 \\
\hline 8 & Aspectos e impactos ambientais & 6,09 & 0,885 \\
\hline 9 & Adequações ambientais & 6,22 & 0,828 \\
\hline
\end{tabular}

Fonte: elaboração própria.

Observa-se que praticamente todas as médias dos fatores indicam que os respondentes concordam em grande parte com afirmativas a respeito das ações da indústria analisada em prol da certificação. No entanto, ressalta-se que apenas o fator 1 apresentou uma média de 5,86, valor que, dentro da escala, significa que há concordância em partes. Isso requer da indústria melhor disseminação aos colaboradores quanto à forma que se conduz a gestão de resíduos, efluentes e químicos na empresa. 
Com relação ao desvio-padrão, os fatores 1, 6, 8 e 9 apresentaram um índice maior, mas ainda estão dentro de níveis aceitáveis para pesquisas com populações grandes. Nesse sentido, Hair Jr. et al. (2008) mencionam que valores pequenos de desvio-padrão, menores que 1,0, significam que os respondentes foram muito coerentes em suas opiniões. No fator 1, as variáveis Q27 e Q23, que trataram sobre a gestão de resíduos e armazenamento de produtos químicos, foram as que apresentaram maior desvio. Já no fator 6 , a variável Q10, que abordou a participação nos treinamentos de conscientização ambiental, apontou um desvio maior.

No fator 8, as duas variáveis, Q20 e Q21, que se referiram aos conhecimentos sobre a tabela do LAIA, indicaram desvio-padrão maior, ainda que o valor não tenha ficado muito distante do ideal. No fator 9, o desvio-padrão foi mais significativo na variável Q05, que abordava as adequações nas atividades diárias para atender aos requisitos ambientais.

Por fim, ressalta-se que, apesar da exclusão de duas variáveis, as médias altas apontam que os colaboradores conhecem os aspectos ambientais, o que pode ter contribuído para a conquista da certificação ISO 14001. Sugere-se apenas que a empresa aperfeiçoe a disseminação de como realiza a gestão de resíduos, efluentes e químicos, pois esses processos existem na indústria pesquisada e são necessários para o atendimento de requisitos ambientais.

\section{CONSIDERAÇÕES FINAIS}

Verificou-se, no decorrer desta pesquisa, que a conscientização ambiental é o cerne de um processo que envolve mudança de cultura e comportamento, como a implantação da certificação ISO 14001. Ao decidir certificar o seu SGA, as organizações precisam estar cientes de que isso envolve transformações significativas, para as quais há necessidade de planejamento e investimentos financeiros.

Nesse sentido, pode-se inferir que o objetivo proposto foi alcançado, pois os fatores foram identificados. Inicialmente, analisou-se o fator gestão de resíduos, efluentes e químicos, o qual demonstrou que nem todos conhecem tais processos, o que pode ser justificado por serem elementos de final de processo, com os quais a maioria dos colaboradores não possui envolvimento direto. No entanto, por ser relevante que todos estejam cientes de como a empresa realiza tais processos, recomenda-se que a indústria pesquisada melhore a conscientização no que concerne a esse fator, até mesmo porque são atividades que possuem grande impacto ambiental.

Os fatores consciência ambiental, educação ambiental e percepção dos danos ambientais, por sua vez, visaram investigar se os colaboradores participaram dos treinamentos de conscientização e se suas ações são reflexos deste processo. Com os resultados, pode-se inferir que os colaboradores participaram dos treinamentos e compreendem os impactos ambientais que diversas atividades da indústria podem trazer. Esse entendimento contribui para que os procedimentos determinados sejam seguidos, evitando-se, assim, incidentes.

Os fatores que trataram da política ambiental e do comprometimento da indústria pesquisada tiveram como finalidade averiguar se os colaboradores conheciam e entendiam as políticas e se a indústria estava comprometida com as questões ambientais. Os resultados mostram que os respondentes estão cientes desse aspecto, pois a política foi formalizada e comunicada a todos em treinamentos e divulgada em murais internos. Também se identificou que os participantes percebem a preocupação da organização com o meio ambiente, o que pode ser considerado um fator positivo, pois traz credibilidade à indústria junto aos seus colaboradores e clientes.

Já no fator destinado à abordar o processo de coleta seletiva e reciclagem, foi possível verificar que os respondentes conhecem a coleta seletiva e realizam a separação de materiais 
adequadamente. Esse fator demonstra que a indústria estudada atingiu o objetivo de conscientizar seus colaboradores.

Quanto ao fator que tratou dos aspectos e impactos ambientais, buscou-se investigar se os colaboradores conheciam o levantamento de aspectos e impactos ambientais, denominado pela indústria analisada como LAIA. Apesar de a maioria sinalizar que sabe onde encontrar o levantamento, muitos disseram não conhecê-lo, o que leva a concluir que ainda há necessidade de disseminação do LAIA, instrumento que auxilia os colaboradores a entenderem os impactos ambientais que suas atividades podem ocasionar.

E, por fim, no fator que buscou conhecer se os colaboradores identificaram a necessidade de adequações ambientais nas suas atividades e no seu ambiente de trabalho, percebeu-se concordância entre os respondentes. Isso significa que a indústria de papel pesquisada teve de passar por alterações que afetaram diretamente os colaboradores.

De modo geral, os resultados do estudo permitem inferir que a indústria investigada conseguiu alcançar um nível de conscientização ambiental que permitiu a conquista da certificação ISO 14001:2004. Assim, infere-se que a conscientização é o caminho para as organizações que desejam implantar esse tipo de certificação, constituindo também elemento fundamental para que mantenha tal conquista de forma duradoura.

Em relação às limitações desta pesquisa, entende-se que, ainda que a proposta do artigo tenha sido levantar os fatores que permitem visualizar que houve disseminação/conscientização dos aspectos ambientais, não foi possível aprofundar os dados coletados devido ao tempo para desenvolvimento deste estudo. Nessa perspectiva, a realização de entrevistas com os colaboradores proporcionaria uma visão mais aprofundada acerca da temática, permitindo compreender de modo mais efetivo os impactos que todo o processo de conscientização trouxe aos colaboradores e, consequentemente, à indústria em questão.

Outra limitação consiste no fato de o questionário ter sido aplicado em uma única empresa, o que não possibilitou comparações de dados, aspecto que enriqueceria ainda mais a pesquisa. A partir disso, sugere-se em estudos futuros analisar casos múltiplos para permitir uma visão mais ampla de processos de conscientização realizados em prol de certificações ambientais.

Salienta-se, ainda, que a principal contribuição desta pesquisa está na definição dos fatores que afetam a conscientização dos colaboradores na implantação da ISO 14001. Tais fatores são importantes tanto para o meio acadêmico, como subsídio a outros estudos, quanto para outras organizações que estejam implementando a certificação. Assim, estudos futuros podem ser realizados em outros setores industriais, para analisar esses fatores em prol da implantação de um SGA de forma bem-sucedida.

\section{AGRADECIMENTOS}

Os autores agradecem à Fundação Araucária de Apoio ao Desenvolvimento Científico e Tecnológico do Estado do Paraná pelo auxílio financeiro à execução dessa pesquisa. 


\section{REFERÊNCIAS}

AGUIAR, A. O. Sistemas de gestão ambiental na indústria química: desempenho, avaliação e benefícios. Tese (Doutorado em Saúde Pública), Universidade de São Paulo, São PauloSP, Brasil, 2004.

ALBERTON, A.; COSTA JUNIOR, N. C. A. Meio ambiente e desempenho econômicofinanceiro: benefícios dos sistemas de gestão ambiental (SGAs) e o impacto da ISO 14001 nas empresas brasileiras. Revista de Administração Contemporânea, RAC, v. 1, n. 2, p. 153-171, 2007.

ALPERSTEDT, G. D.; QUINTELLA, R. H.; SOUZA, L. R. Estratégias de gestão ambiental e seus fatores determinantes: uma análise institucional. Revista de Administração de Empresas, RAE, v. 50, n. 2, p. $170-186$, abr./ jun. 2010.

ASSOCIAÇÃO BRASILEIRA DE NORMAS TÉCNICAS. NBR ISO 14001. Sistemas da gestão ambiental - Requisitos com orientações para uso. ABNT: Rio de Janeiro, 2004. Disponível em: <http://www.labogef.iesa. ufg.br/labogef/arquivos/downloads/nbriso-14001-2004_70357.pdf> Acesso em: 21 jun. 2015.

BARTHOLOMEU FILHO, J.; AGUIAR, A. O. Implantação e Sistema de Gestão Ambiental: experiências e perspectivas de uma Corporação. In: ENCONTRO INTERNACIONAL SOBRE GESTÃO EMPRESARIAL E MEIO AMBIENTE, 15, São Paulo, 2013. Anais... São Paulo: ENGEMA, Setembro, 2013.

BORBA, A. C. O. Avaliação do sistema de gestão ambiental nas indústrias beneficiadoras de cacau no Sul da Bahia. Dissertação (Mestrado em Desenvolvimento Regional e Meio Ambiente). Universidade Estadual de Santa Cruz, Ilhéus- BA, 2007.
BRASIL. Lei no 6.938, de 31 de agosto de 1981. Dispõe sobre a Política Nacional do Meio Ambiente, seus fins e mecanismos de formulação e aplicação, e dá outras providências. Disponível em: <https://www. planalto.gov.br/ccivil_03/leis/I6938.htm> Acesso em: 25 abr. 2015.

CAPPARELLI, H. F. Sistema de gestão ambiental e produção mais limpa: Análise de práticas e interação dos sistemas. Dissertação (Mestrado em Ciências da Engenharia Ambiental), Universidade de São Paulo, São Carlos- SP, Brasil, 2010.

CARDOSO, L. C.; ALVES, P. H. C.; MONDO, T. S.; COSTA, J. I. P. Gestão ambiental como diferencial na imagem corporativa: estudo multicaso em meios de hospedagem do município de Urubici - SC. Revista Turismo e Ação, v. 15, n. 1, p. 6-20, jan./abr. 2013.

COOPER, D. R.; SCHINDLER, P. S. Métodos de Pesquisa em Administração. Tradução: luri Duquia Abreu. 10. Ed. Porto Alegre: Bookman, 2011.

CRESWELL, J. W. Projeto de pesquisa: métodos qualitativo, quantitativo e misto. 3.ed. Porto Alegre: Artmed/Bookman, 2010.

DARNALL, N. "Why firms mandate ISO 14001 certification". Business \&Society, v. 45, n. 3, p. 354-381, 2006. Disponível em: <http://search.proquest.com/docview/199386721/6E5986B3B5704461PQ/1 ?accountid=42153> Acesso em: 24 ago. 2017.

DICIONÁRIO ONLINE DE PORTUGUÊS. Disponível em: <https://www.dicio.com.br> Acesso em: 25 ago. 2017.

FERREIRA, M. C.; Gestão Ambiental: um estudo em empresas do setor sucroalcooleiro em Goiás. Revista Pensamento Contemporâneo em Administração, v. 7, n. 3, p. 59-80, jul./set. 2013. Disponível em: <http://www.uff.br/pae/ index.php/pca/article/view/264/198> Acesso em: 23 ago. 2017. 
FIELD, A. Descobrindo a estatística usando o SPSS. 2 ed. Porto Alegre: Artmed, 2009.

GAVRONSKI, I. Gestão estratégica de operações sustentáveis: levantamento das empresas brasileiras certificadas na norma NBR ISO 14001. Dissertação (Mestrado em Administração), Universidade do Vale do Rio dos Sinos, São Leopoldo- RS, Brasil, 2003. Disponível em: <http://search.proquest.com/business/docview/1399484749/abstract/2B253C305C864997PQ/1?accountid $=42153 \#$ center $>$ Acesso em: 28 jun. 2015.

HAIR JR., J. F.; BABIN, B.; MONEY, A. H.; SAMOUEL, $P$. Fundamentos de métodos de pesquisa em administração. Porto Alegre: Bookman, 2008.

HERAS-SAIZARBITORIA, I; LANDÍN, G. A.; MOLINA-AZORÍN, J. F. Do drivers matter for the benefits of ISO 14001? International Journal of Operations \& Production Management, v. 31, n. 2, p. 192- 216, 2011. Disponível em: http:// search.proquest.com/docview/840141458/ abstract/F521002CA38548ADPQ/4?accounti$d=42153>$ Acesso em: 20 ago. 2017.

JABBOUR, C. J. C.; SANTOS, F. C. A. Empowerment dos funcionários e níveis de maturidade da gestão ambiental nas empresas: um modelo conceitual. Revista de Administração da UFSM, Santa Maria, v. 6, n. 3, p. 497-510, set. 2013.

JERÔNIMO, C. E. M. Diagnóstico da gestão ambiental em microempresas e empresas de pequeno porte da cidade de Manaus-AM. Revista Mestrado em Administração, v. 6, n.1, p. 71-90, out. 2013/mar. 2014.

KUSHWAHA, G. S. Sustainable development through strategic green supply chain management. International Journal of Engineering and Management Sciences, v. 1, n. 1, p. 07-11, 2010.Disponível em: <http:// www.scienceandnature.org/First_IJEMS_ upload/IJEMS_V1\%281\%292.pdf> Acesso em: 20 ago. 2017.
LOPES, L. J.; SACOMANO NETO, M.; ARGOUD, A. R. T. T.; CAMARGO JUNIOR, J. B.; PIRES, S. R. I. Uma análise das práticas de Green Supply Chain Management e certificação ISO 14001 no setor automobilístico brasileiro. Revista de Administração da UNIMEP, v. 13, n.1, p. 165188, jan./Abr., 2015.

MALHOTRA, N. K. Pesquisa de marketing: uma orientação aplicada. 4. ed. Porto Alegre: Bookman, 2006.

MAROCO, J. Análise estatística - com utilização do SPSS. 2 ed. Lisboa: Edições Sílabo, 2003.

MATTIOLO, S. R. Diretrizes para implantação de um Sistema de Gestão Ambiental no ciclo do combustível nuclear: estudo de caso da USEXA- CEA. Tese (Doutorado em Ciências na Área de Tecnologia Nuclear- Materiais), Universidade de São Paulo, São Paulo- SP, Brasil, 2012.

MAZZA, C.; ISIDRO- FILHO, A.; HOFFMANN,V. E. Capacidades dinâmicas e inovação em serviços envolvidas na implementação e manutenção de práticas de sustentabilidade empresarial. Revista de Administração e Inovação, RAl, v. 11, n. 1, p. 345- 371, jul./set. 2014.

NEVES, E. B.; ROZEMBERG, B. Estudo comparativo entre o sistema de gestão ambiental do exército brasileiro e a norma ISO 14001. Revista de Gestão Social e Ambiental, RGSA, v. 4, n. 1, p. 159-177, 2010.

OLIVEIRA, O. J.; PINHEIRO, R. M. S. Implantação de sistemas de gestão ambiental ISO 14001: uma contribuição da área de gestão de pessoas. Revista Gestão e Produção, São Carlos, v. 17, n. 1, p. 51-61, 2010. Disponível em: <http://www.scielo.br/pdf/gp/v17n1/ v17n1a05> Acesso em: 21 jun. 2015.

OLIVEIRA, O. J.; SERRA, J. R. Benefícios e dificuldades da gestão ambiental com base na ISO 14001 em empresas industriais de São Paulo. Revista Produção, v. 20, n. 3, p. 429-438, jul./set. 2010. Disponível em: 
<http://www.scielo.br/pdf/prod/v20n3/aop_ T6_0009_0078.pdf> Acesso em: 19 abr. 2015.

PELLICER, E.; YEPES, V.; CORREA, C.; MARTÍNEZ, G. Enhancing R\&D\&i through standardization and certification: the case of the spanish construction industry. Revista Ingeniería de Construcción, v. 23, n. 2, p. 112-121, ago. 2008.

QUINTANA, A. C.; MACHADO, D. G.; AMARAL, T.; QUINTANA, C. G. Gestão Ambiental: produção científica divulgada em periódicos nacionais qualis B1 a B4 - Capes. Revista de Administração e Inovação, RAI, v. 11, n. 2, p. 07-29, abr./ jun. 2014.

Serviço Brasileiro de Apoio às Micro e Pequenas Empresas, SEBRAE. Anuário do trabalho na micro e pequena empresa. 2013. Disponível em: <http://m.sebrae.com.br/ Sebrae/Portal\%20Sebrae/UFs/SP/Pesquisas/ MPE_conceito_empregados.pdf> Acesso em 25 ago. 2017.

TO, W. M.; TANG, M. N. F. The adoption of ISO 14001environmental management systems in Macao SAR, China Trend, motivations, and perceived benefits. Management of Environmental Quality, v. 25, n. 2, p. 244-256, 2014. Disponível em: <http://search.proquest. com/business/docview/1508379359/ FEDA06A89E6C4B68PQ/2 ?accountid=42153> Acesso em: 01 jul. 2015. 